University of Louisville

ThinkIR: The University of Louisville's Institutional Repository

Electronic Theses and Dissertations

$5-2010$

\title{
Simulation-based metrics analysis of an outpatient center.
}

Elvin Webb

University of Louisville

Follow this and additional works at: https://ir.library.louisville.edu/etd

\section{Recommended Citation}

Webb, Elvin, "Simulation-based metrics analysis of an outpatient center." (2010). Electronic Theses and Dissertations. Paper 1542.

https://doi.org/10.18297/etd/1542

This Master's Thesis is brought to you for free and open access by ThinkIR: The University of Louisville's Institutional Repository. It has been accepted for inclusion in Electronic Theses and Dissertations by an authorized administrator of ThinkIR: The University of Louisville's Institutional Repository. This title appears here courtesy of the author, who has retained all other copyrights. For more information, please contact thinkir@louisville.edu. 


\title{
Elvin Webb
}

Bachelor of Science in Industrial Engineering, University of Louisville May 2009

\author{
A Thesis \\ Submitted to the Faculty of the \\ University of Louisville \\ J. B. Speed School of Engineering \\ as Partial Fulfillment of the Requirements \\ For the Professional Degree
}

\section{MASTERS OF ENGINEERING}

Department of Industrial Engineering

May 2010 


\section{SIMULATION-BASED METRICS ANALYSIS OF AN OUTPATIENT CENTER}

Submitted by:

Elvin Louis Webb

A Thesis Approved On

(Date)

by the Following Reading and Examination Committee:

Dr. Gail DePuy, Thesis Director

Dr. Gerald Evans

Dr. Tim Hardin 


\section{ACKNOWLEDGMENTS}

The author wishes to take this time to thank the University of Louisville Outpatient Center for providing the opportunity to complete this thesis. The support and knowledge gained from the center's staff was essential to the completion of this project.

He would also like to thank the thesis examination committee members who gave generously of their time to review this thesis. In addition, for their insight and expertise, Dr. Gerald Evans, Dr. Tim Hardin, and Dr. Aldo McLean are greatly appreciated. Finally, the author would like to thank Dr. Gail DePuy for her guidance and support along this journey. 


\begin{abstract}
With more and more attention surrounding healthcare, Industrial Engineers have championed the task to help hospitals and outpatient centers operate as efficiently as possible. Simulation is often used to analyze hospital performance measures.

The University of Louisville Health Care Outpatient Center is a relatively new building occupying 169,000 $\mathrm{ft}^{2}$ and opened in October of 2008. The clinic is experiencing uneven workloads, over scheduling of Medical Assistants, and highly variable patient waiting times.. The Arena Simulation package has been used to develop a model of the outpatient center's current state. Using the data from July 2009 the model has been validated and verified. The model uses actual patient arrival data and discrete probability distributions to describe the current patient processing scheme for 41 doctors who regularly operate out of the outpatient center. Utilization rates for doctors were generally very high, but great variability was also present. Room utilization rates were lower than the author expected, confirming that the clinic could potentially house more doctors. Medical Assistants (MA) and doctors had almost equal numbers of patients waiting for them so it can be suggested that when deciding staffing levels MAs and doctors should be added at a one to one ratio. Patient waiting times were also highly variable based on which doctor was being visited and it was suggested that the current doctors review their scheduled patient visit times to make sure they are scheduling for an accurate time. Further research can be done to increase usability and add animation to the model.
\end{abstract}




\section{TABLE OF CONTENTS}

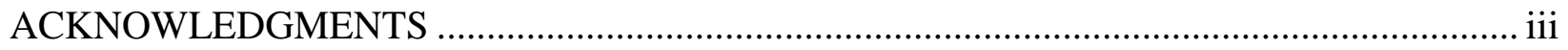

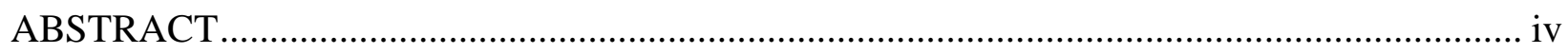



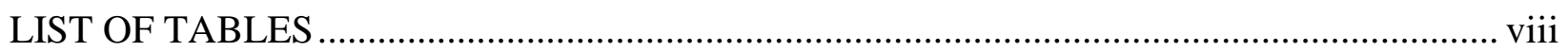





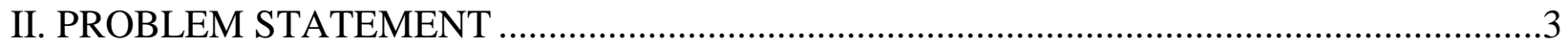

III. LITERATURE REVIEW ........................................................................................

A. GENERAL USES FOR SIMULATION IN HEALTHCARE ..........................................5

B. SIMULATION IN OUTPATIENT CENTERS ............................................................

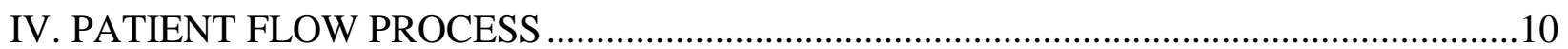

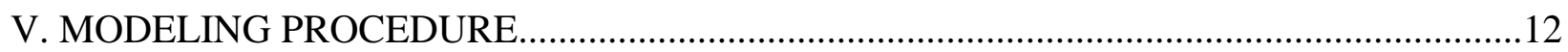

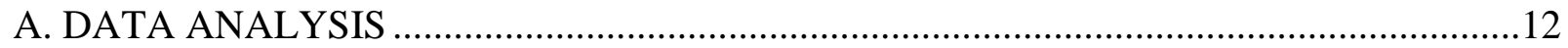

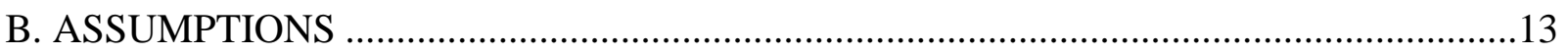

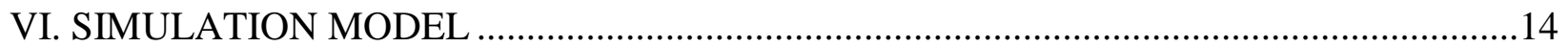

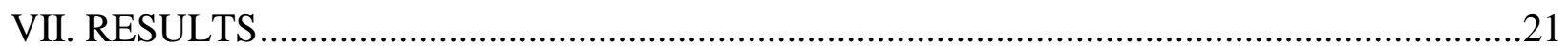

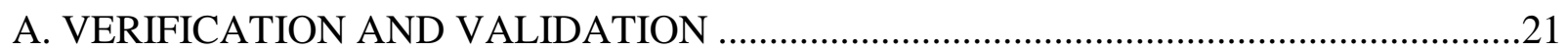



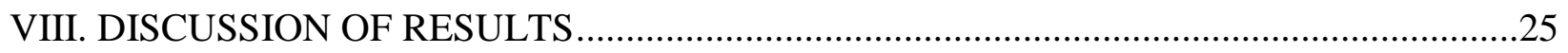

IX. CONCLUSIONS, RECOMMENDATIONS, and FUTURE RESEARCH............................. 27

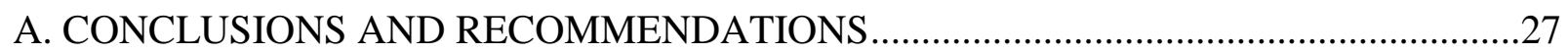



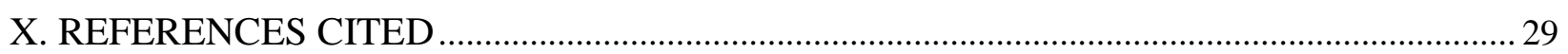

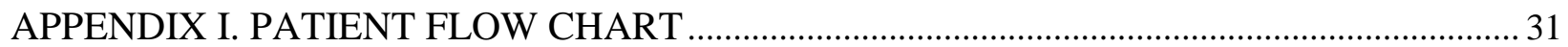



APPENDIX III. EXPECTED PATIENTS COMPARED TO CREATED ENTITIES .................. 33 


\section{NOMENCLATURE}

\section{1.) Simulation Related Nomenclature:}

Entity-person or object moving through the simulation model that is being acted upon and utilizing resources

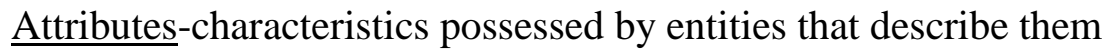

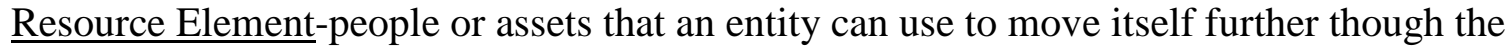
simulation

Queue-line where entities will wait for a resource if the resource is busy

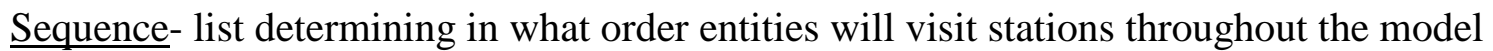

$\underline{\text { Schedule Element-spreadsheet where resource availability or arrival schedule can be outlined }}$

Create Module-generates entities and releases them into the system based on schedule or time between arrivals

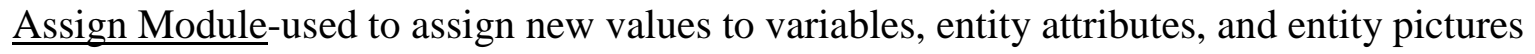
$\underline{\text { Record Module-collects statistics throughout the model }}$

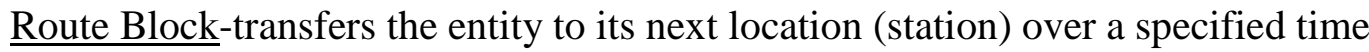
$\underline{\text { Station Block-locations to which entities are routed based upon a specified sequence }}$

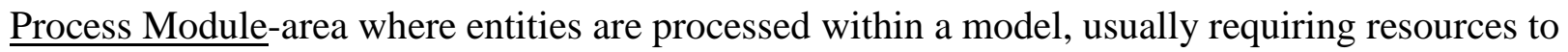
be seized. Processes can be classified as value added, non-value added, wait, or transfer. Decide Module-point at which decisions are made based on conditions or probabilities in a model, used to bring logic into the simulation 


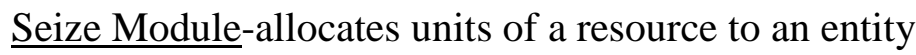

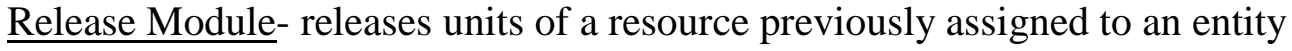

Dispose Block-removes entities from the simulation and counts them and being finished

\section{2.) Outpatient Center Related Nomenclature}

Medical Assistant-brings the patient back to the exam room and takes notes of their history and basic vital signs

Physician- works directly with the patient to understand illness, diagnose problems, and prescribe medications or future visits

Check-in nurse-checks the patient into the system and updates any new insurance or patient information

Check-out nurse-sets up future visits and checks the patient out of the system

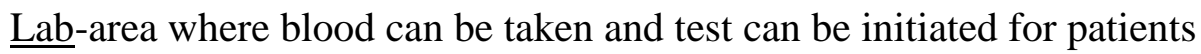




\section{LIST OF TABLES}

TABLE I: SAMPLE DATA ....................................................................................................................... 12

TABLE II: PATIENT ARRIVAL SCHEDULE.............................................................................................

TABLE III: PROBABILITY DISTRIBUTIONS FOR DOCTORS ...................................................... 18 


\section{LIST OF FIGURES}

Figure 1: Layout of University of Louisville Outpatient Center ............................................................2

Figure 2: Utility Curve for Model Complexity (Miller et al., 2008) ....................................................... 7

Figure 3: Arrival Section of Arena Module...................................................................................................... 16

Figure 4: Check-in, Patient Type Identification, and Routing Logic in Arena................................... 17

Figure 5: Patient Routing, Seizure, Processing, and Release Modules in Arena................................ 18

Figure 6: Check Out and Dispose Module for Patient Exit ..................................................................19

Figure 7. Real Time Model Statistics Section in Arena......................................................................20

Figure 8. Expected vs. Created Patients for July 2009............................................................................22

Figure 9. Acutal vs. Simulated Time in System...................................................................................................22

Figure 10. Resource Utilization Rates by Day of Week .................................................................................25 


\section{INTRODUCTION}

The University of Louisville's Outpatient Center is a relatively new area for doctors to see patients outside the hospital. It was opened in 2008, and is staffed by 11 medical assistants and 45 doctors, 36 of whom see patients on a regular basis. The doctors operating out of the outpatient clinic specialize in many varied fields of medicine including, cardiology, endocrinology, gastrointestinal diseases, infectious diseases, pulmonary problems, and rheumatology. There are 24 exam rooms, 2 nurse stations, 4 doctor rooms, 2 labs, and a patient waiting room all within $169,000 \mathrm{ft}^{2}$. Figure 1 below shows the layout of the outpatient facility. 




Figure 1: Layout of University of Louisville Outpatient Center

The office operates 2 half-day shifts, from 8:00 to 12:00 and from 12:30 to 4:30. Typically each half-day will have 8 doctors scheduled, with Tuesday and Wednesday being the busiest days in the office. Patients are scheduled mainly around the availability of the doctor at the specified clinic. Appointment durations are usually set for either a shorter time or a longer time based upon doctor's recommendations. Some doctors use 20 minutes and 40 minutes, while some prefer to use 30 minutes and 1 hour. Anywhere from 5 to 30 patients are seen within a given half-day. Doctors can see anywhere between 2 and 20 patients in a half-day based on the 
amount of time they spend with the patient. Medical Assistants are assigned to specific doctors, usually 4-6 doctors per day.

The remainder of this thesis is organized as follows. In the next section the problem is described in greater detail, focusing on important performance metrics. The review of related literature provides an in-depth survey of current uses of simulation in health care and simulations within outpatient clinics. Following the literature review, patient flow is described throughout the entire outpatient system. Data analysis techniques and necessary assumptions are detailed in the modeling procedures section. The simulation logic and model are discussed within the simulation model section. The results section shows output from the Arena model and outpatient performance metrics are analyzed. Finally, conclusions are presented with recommendations for the outpatient center and future research in the area.

\section{PROBLEM STATEMENT}

Although this is a newer facility, problems have surfaced over its year and half of operation. As previously mentioned, Tuesdays and Wednesdays are the busiest days because doctors rarely want to work on Mondays or Fridays. This creates much extra stress and work for the Medical Assistants (MAs) on those days. Some doctors see many more patients on a given half-day than others, resulting in unequal workload assignments for the MAs. The operating schedule typically is catered to the desires of the doctors, and efficiency is often the second item considered. This clinic does not seem to record or focus on any particular performance measure.

The outpatient clinic is currently in a state that can support day-to-day function, but does not lend any opportunities for data driven improvements. The center is hesitant to make large 
operational changes because they are often costly and there is no data analysis to predict a known outcome. A system that provides analysis of current state operations and quantifies the value of potential changes is lacking from the clinic. Utilization rates for doctors, Medical Assistants, and rooms are often unknown. The absence of key operational metrics such as throughput, utilization, and patient waiting times makes it almost impossible for the center to make improvements. For example, a common belief held by hospital management is that the center could have more doctors operate clinics within their facility than are currently scheduled. Without understanding room and MA utilization rates, the impact on patient waiting times and throughput could not be measured. Understanding and using these measures will make resource planning and allocation much easier.

This thesis will address the information problems through the simulation model. Medical assistant, check-in, and check-out staff utilization rates will be provided through the simulationbased model. Patient waiting times, total time in system, and time spent waiting for resources will be observed for the simulated month. These performance measures will be instrumental in driving decisions to improve the outpatient center's daily operations. 


\section{LITERATURE REVIEW}

This literature review addresses two main topics; how simulation has been applied within the health care field and how simulation has been directly used within outpatient centers. General uses for simulation in healthcare seeks to provide insight into types of simulation techniques, detail level in simulation, an Arena simulation of an emergency department, and a simulation incorporating human behavior. Simulation in outpatient centers will discuss trend of shifting care to outpatient clinics, early outpatient simulation, an outpatient center simulation using actual data, and an outpatient simulation using probability distributions. The literature presented in this review should give a general overview of how simulation can benefit health care and various applications in outpatient clinics.

\section{A.) General Uses for Simulation in Healthcare}

For much time simulation has been a staple tool in the manufacturing and business arenas. After years of success in other fields, the health care industry has started to adopt simulation for process analysis and more informed decision-making. Simulation is a valuable asset to the health care industry because it not only allows the estimation of operational characteristics, but also estimates the consequences of making changes in planning or policies, therefore reducing financial risk (Jun et al., 1999). According to Kuljis et al. (2007), performance metrics are being introduced to better understand change in heath care, but often progress in one area comes at the expense of other equally important metrics.

The purpose of this simulation model is to give insight into all performance metrics surrounding the outpatient center and how they are impacted by systematic changes. Kuljis et al. (2007) 
describe the six major techniques in simulation: discrete-event, continuous, system dynamics, Monte Carlo, agent-based simulation, and 3-D and virtual reality simulation, and how they have been used in manufacturing and how they could potentially be used in health care. Most importantly the article discusses how discrete-event simulation has been used for increasing productivity, reducing waiting times, and job scheduling, all techniques that can be applied to health care simulation. The simulation in this thesis uses discrete-event simulation (DES) due to its ability to model sequential events easily and the availability of DES software.

Patient scheduling is of major importance when working in the health care field. Well-planned patient scheduling can decrease waiting time while increasing utilization. Bakker et al (2008), Dexter (1999), Liu (1998), and Takakuwa (2008) discuss patient appointment scheduling based around simulation modeling. Both Arena and Excel simulation models were use to study current patient scheduling schemes and virtually implement new schemes. The simulations that were studied in these articles used real data to describe patient arrivals and validate the models. Stochastic distributions were commonly used other places within the simulations. When working with patient scheduling, it is common to develop more than one model and test out multiple ideas to see the potential impact to the system. Simulation has made it much easier for modelers to change scheduling functions and selection rules to see if changes would help improve waiting times for patients.

Determining the amount of detail and data to include in a model is an important step in deciding the logic behind a simulation model. Miller et al. (2008) notes that adding more complexity to a simulation model does not necessarily add value to the final analysis. They go on to state that 
too much complexity is actually counterproductive because it requires much more time and effort to ensure the model is performing like the real system. Figure 1 below shows that as complexity increases utility will increase. This trend continues until utility reaches a maximum after which further complexity will only diminish utility.

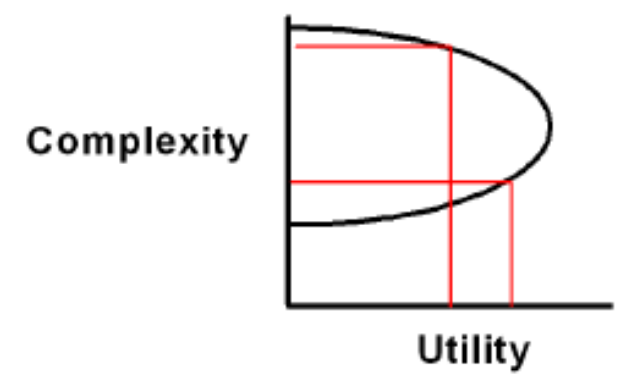

Figure 2: Utility Curve for Model Complexity (Miller et al., 2008)

Model detail level is especially crucial for health care simulation models since available data is often less than desired and assumptions are often required to model reality.

Industrial Engineers are always looking to improve efficiency by coming up with innovative ideas to provide a competitive edge in industry. These innovations have spread into the health care field and hold much promise for reducing waste and increasing throughput and patient satisfaction. A study based around an Emergency Department presented the new idea of Provider Directed Queuing (PDQ) that assigns an emergency room physician to a patient at triage, and based on the physician's initial assessment will then assign the patient a traditional room or simply order treatments that may not necessarily require a room (DeFlitch, 2008). Although the Arena simulation model for the PDQ situation chose not to directly model human activities, research exists that supports simulation modeling for human behavior. Brailsford et 
al. (2006) completed a Discrete Event Simulation (DES) to aid health care managers in deciding whether or not to invest in potential treatments and technologies. The model utilizes breast cancer data from the UK along with a survey given to 2058 random women in the UK to predict how certain women will react to certain potential treatments.

\section{B.) Simulation in Outpatient Centers}

According to Jun et al. (1999), the movement from delivering health care services in inpatient facilities to outpatient facilities has driven the expansion of many hospitals outpatient services. It goes on to state that due to the complexity of integrated systems such as an outpatient center and the large amount of data required to support a simulation based around such a facility, there are very few articles discussing the use of simulation for these complex integrated systems. One of the first simulations of an outpatient clinic dates back to a study done by Fetter and Thompson in 1965 in which it was found that a 30\% increase in doctor utilization rates could only be justified if the doctor's time was worth ten times that of the patient (Jun et al., 1999).

An article describing a simulation performed at the University Hospital and Medical Center at Stony Brook in New York's outpatient clinics emphasizes the use of real data in simulation modeling and verification. Real data was chosen over distribution functions and predetermined industry time standards because the staff was confident that the data was accurate and using real data helped to further staff confidence in the model (Barnes et al., 1997). On the other hand, an article describing an Arena simulation of a new Pain Management Outpatient Procedure Center (OPC) within the Mayo Clinic used real data over a one year time period to create probability distribution estimates for each processes. The Mayo Clinic simulation also presented the idea of applying a hedge, or adding extra time to mean processing times to account for variability 
(Denton et al., 2008). There are obviously two schools of thought based around how to use data within simulation models. It should be noted that simulation modeling for outpatient clinics is not a common as simulation in other branches of health care, but there is literature available to support and document its uses. 


\section{PATIENT FLOW PROCESS}

The patient flow process at the outpatient clinic is as follows. Patients arrive based on appointment time to the $3^{\text {rd }}$ floor of the building in downtown Louisville. Upon arrival, patients check in with a member of 2 or 3 person check-in team. The patient's information is updated within the IDX Web Framework information system to reflect any changes that may have occurred since the last visit. If the patient is new they will fill out a health questionnaire. The check-in team member will then tell them to wait in the waiting room until they are called back to an exam room.

After the patient has signed in and the check-in staff has printed and updated the demographic and insurance information, they will take the chart to the nurses/MA station. The MA assigned to the doctor seeing the patient will take the folder and call the patient back to an exam room assigned to that particular doctor. Prior to being taken to an exam room, the patient may be taken to triage where their height, weight, temperature, blood pressure, and oxygen levels will be taken. Once the patient is waiting in the room, the MA will write the patient's name on the doctor's board along with their room number and if they are a follow up or new patient. The MA

will put the folder in the box outside the door and move out a plastic tab signaling that the patient is ready to be seen.

The doctor will work with the patient and decide if they need future visits or any medications. After the assessment, the doctor will give the MA a feed ticket and the chart. The MA will then route the patient to the check-out station. The feed ticket will state when the patient needs to 
come back for a follow up visit and some doctors will simply tell the patient when to reschedule. Often patients will want to check their schedules before they make their next appointment and will call them in by phone. Finally after all insurance info and billing questions are finished; the patient is released from the system. 


\section{MODELING PROCEDURES}

\section{A. Data Analysis}

Good data is often difficult to find in some health care systems. It must be noted that patient privacy is of extreme importance when dealing with data collection and analysis within the health care arena. The outpatient facility's IT staff was able to provide a year's worth of very useful data to support this thesis. This data included scheduled appointment date, appointment time, arrival time of patient, departure time, scheduled appointment duration, doctor associated with appointment, and whether the patient arrived, was bumped, canceled or was a no show. A sample output of this data can be seen in table I.

\section{TABLE I: SAMPLE DATA}

\begin{tabular}{|c|c|c|c|c|c|c|c|c|c|c|c|c|c|c|}
\hline 4 & $B$ & c & D & $E$ & $\mathrm{~F}$ & & G & H & 1 & 1 & $\mathrm{k}$ & L & & $M=$ \\
\hline 1 & Sch Session $\square$ & Sch Cancel Reason & Sch Datetime $\pi$ & Sch SchStatusDese $\pi$ & Sch CanReason & $\nabla$ & SchDateld Act -1 & Sch ArrivedTime $\nabla \mathrm{s}$ & Sch PtCkOutTime - & Sch CanfBmp Commer - & Sch Lag & Sch Duration & $\nabla$ & \\
\hline 13421 & AM & & 711622009 11:00 & Arrived & & & 71662009 & $7 / 161200910: 10$ & 7116220091112 & & & 32 & 60 & \\
\hline 13422 & AM & & $71616200910: 00$ & Arrived & & & 71662009 & 7h6t22009 10:10 & 7116620099 11:12 & & & 32 & 60 & \\
\hline 13424 & $\mathrm{PM}$ & & $71291200915: 00$ & Arrived & & & 712912009 & 712912009 15:14 & $71291200915: 40$ & & & 45 & 15 & \\
\hline 13426 & PM & & 772222009 14:00 & Arrived & & & 712212009 & $77221200914: 13$ & 7122212009 14:44 & & & 40 & 30 & \\
\hline 13437 & PM & & $76612009913: 20$ & Arrived & & & 76612009 & $7761200913: 14$ & $77612009913: 35$ & & & 37 & 15 & \\
\hline 13438 & PM & & $72727200913: 40$ & Arrived & & & 7127272009 & 72727200913.59 & $71271200915: 33$ & & & 50 & 15 & \\
\hline 13455 & PM & & $7616200912: 30$ & Arrived & & & 77612009 & 7161200911158 & $76622009913: 01$ & & & 20 & 30 & \\
\hline 13456 & PM & & $78: 22009914: 20$ & Arrived & & & 7882009 & $7881200914: 38$ & & & & 21 & 60 & \\
\hline 13462 & AM & & $722120099: 00$ & Arrived & & & 7212009 & $721220099: 17$ & $72122009911: 22$ & & & 21 & 60 & \\
\hline 13478 & PM & & $71+1200914: 40$ & Arrived & & & $7+112009$ & $7+11200914: 25$ & $71+200915: 45$ & & & 35 & 60 & \\
\hline 13494 & PM & & $7882009912: 30$ & Arrived & & & 7882009 & $78 \$ 200910: 15$ & $78 \$ 12009912: 22$ & & & 45 & 15 & \\
\hline 13495 & AM & & $7882009910: 30$ & Arrived & & & 7882009 & $7881200910: 15$ & $78182009912: 22$ & & & 45 & 60 & \\
\hline 13497 & PM & & 711420099 & Arrived & & & 711422009 & $71 / 4200910: 14$ & 711422009 11:10 & & & 50 & 30 & \\
\hline 13498 & $\mathrm{AM}$ & & $7114200990: 30$ & Arrived & & & 71142009 & $7141200910: 14$ & 714142009 11:10 & & & 50 & 60 & \\
\hline 13504 & PM & & $7133200994: 00$ & Arrived & & & 771312009 & 71132009 14:01 & $7133200916: 50$ & & & 50 & 60 & \\
\hline 13516 & PM & & $7 / 2912009$ 12:40 & Arrived & & & 712912009 & $7299200991: 48$ & $729212009155: 40$ & & & 65 & 45 & \\
\hline 13549 & PM & & 77301200995.50 & Arrived & & & 713012009 & $73301200916: 51$ & $713012009917: 24$ & & & 0 & 20 & \\
\hline 13550 & PM & & $73301200995: 30$ & Arrived & & & 733012009 & $73301200916: 51$ & 773012009 17:24 & & & 0 & 15 & \\
\hline 13551 & PM & & $71512200912: 30$ & Arrived & & & 715152009 & 7115/2009 12:03 & & & & 0 & 60 & \\
\hline 13556 & PM & & $71272009914: 40$ & Arrived & & & 7127272009 & $7 / 272000914: 38$ & $7127200095: 34$ & & & 0 & 15 & \\
\hline 13558 & PM & & $7 / 3121200913: 30$ & Arrived & & & 713112009 & $7 / 3122009$ 13:10 & $7 / 3121200995: 00$ & & & 3 & 60 & \\
\hline 13559 & PM & & $71271200995: 30$ & Arrived & & & 7127272009 & $7127200995: 51$ & 7727272009 16:02 & & & 0 & 15 & \\
\hline 13574 & PM & & 712322009 15:00 & Arrived & & & 712322009 & 712322009 15:07 & 723232009 16:06 & & & 1 & 60 & \\
\hline 13576 & $\mathrm{AM}$ & & 7/3112009 10:00 & Arrived & & & 773112009 & $7731120098: 33$ & 7/3112009 12:17 & & & 6 & 30 & \\
\hline 13577 & $\mathrm{AM}$ & & $7 / 31120099: 00$ & Arrived & & & 71/1120099 & $7 / 31120098: 32$ & 7/3112009 12:17 & & & 6 & 60 & \\
\hline 13578 & PM & & 727272009 15:00 & Arrived & & & 712772009 & 712712009 15:00 & $72727200915: 34$ & & & 4 & 15 & \\
\hline 13581 & PM & & $7 / 15 / 200914: 20$ & Arrived & & & 715122009 & 7715120009 14:26 & 7115220099518 & & & 0 & 15 & \\
\hline 13582 & $P M$ & & $7 / 1512009913: 40$ & Arrived & & & 715152009 & 771512009 14:00 & 7151520091518.18 & & & 0 & 15 & \\
\hline 13585 & $\mathrm{AM}$ & & 7/2120009 10:20 & Arrived & & & 712112009 & $77121200910: 30$ & $721212009911: 16$ & & & 4 & 60 & \\
\hline 13586 & PM & & $73002009912: 30$ & Arrived & & & $7 / 3012009$ & $733012009911: 27$ & $7 / 30120099$ 12:01 & & & 11 & 30 & \\
\hline 13587 & AM & & 773012009 11:00 & Arrived & & & $7 / 3012009$ & $73302200911: 27$ & 7730120099 12:01 & & & 11 & 15 & \\
\hline 13592 & $A M$ & & 7121212009 11:00 & Arrived & & & 712:22009 & $7212120099: 13$ & $7121200999: 33$ & & & 6 & 15 & \\
\hline 13593 & AM & & 7221200910000 & Arrived & & & 72122009 & $721220099: 13$ & $72212009911: 15$ & & & 6 & 60 & \\
\hline 13596 & PM & & $72991200913: 30$ & Arrived & & & 712912009 & $712912009913: 00$ & $7299200995: 40$ & & & 26 & 60 & \\
\hline 13599 & $\mathrm{AM}$ & & $712727200911: 10$ & Arrived & & & 712712009 & $7 / 2712009910: 47$ & $71271200910: 55$ & & & 25 & 15 & \\
\hline 13610 & PM & & $71212200913: 20$ & Arrived & & & 712112009 & 712122009 12:24 & $7 / 2121200913: 17$ & & & 9 & 60 & \\
\hline 13612 & PM & & 7200200991250 & Arrived & & & 712012009 & $71201200912: 28$ & $77201200992: 48$ & & & 7 & 15 & \\
\hline 13614 & PM & & $7 / 132200913: 10$ & Arrived & & & 7113120099 & $7 / 132200913: 15$ & $7 / 132200913: 44$ & & & 0 & 15 & \\
\hline 13615 & $\mathrm{AM}$ & & $711420099: 20$ & Arrived & & & 71142009 & $711420098: 42$ & 71/412009 11:10 & & & 1 & 60 & \\
\hline 2619, & $=m$ Pivot Tal & s) Sheet 3 / \& & the & ne & & & (1) & 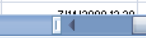 & Thumannnuen an & & & $x^{2}$ & & 10 \\
\hline
\end{tabular}


This data will be used to develop an average month for the outpatient clinic. Since some doctors do not hold clinics every week so a month time frame was chosen to incorporate all potential issues. After studying the data, July appears to be a good representation of almost all the doctors and patient types. July will shows unique situations where some doctors are seeing patients multiple days per week and some doctors only see patients one day per month. The scheduled duration data will also be used to set up probability distributions for patient servicing time.

\section{B. Assumptions}

This simulation model, as with most, will make assumptions to allow for a close to reality as possible modeling situation.

-Patients are serviced based on scheduled appointment duration.

-Arrivals will occur based on a monthly schedule derived from historical data.

-Only patient arrivals will be included in the system. Patients who are bumped, do not show, or are cancelled will have no impact on this simulation model.

-Patients will be assigned a MA and exam room randomly. 


\section{SIMULATION MODEL}

\section{A. Logic}

The logic behind this simulation model attempts to align itself as closely as possible to the actual patient flow chart in Appendix II. This simulation model can be classified as a dynamic, discrete change, stochastic model. Dynamic refers to the fact that time plays an important role throughout the model. Discrete change or discrete event simulation, allows changes within the model to be driven by events and not continuous. This model introduces stochastic elements when distribution functions are used to describe patient processing times and check in and out times.

Patients arrive according to a schedule via a create module in Arena. Time between arrivals is assumed to be an exponential distribution function. A random variate generated from a Poisson distribution function is used to give the number of arrivals within a unit of time. Table II shows a sample monthly schedule for 1 doctor's patient arrivals in the system. 


\section{TABLE II. PATIENT ARRIVAL SCHEDULE}

\begin{tabular}{|c|c|c|c|c|c|c|c|}
\hline & & & 1 Wednesday & & Thursday & 3 & \multirow{10}{*}{$x^{\infty}$} \\
\hline \multicolumn{7}{|l|}{$8: 00-9: 00$} & \\
\hline \multicolumn{7}{|l|}{$9: 00-10: 00$} & \\
\hline \multicolumn{7}{|l|}{$10: 00-11: 00$} & \\
\hline \multirow{2}{*}{\multicolumn{7}{|c|}{\begin{tabular}{r|}
$11: 00-12: 00$ \\
$12: 00-1: 00$
\end{tabular}}} & \\
\hline & & & & & & & \\
\hline \multicolumn{7}{|l|}{$1: 00-2: 00$} & \\
\hline \multicolumn{7}{|l|}{$2: 00-3: 00$} & \\
\hline \multicolumn{7}{|l|}{$3: 00-4: 00$} & \\
\hline \multirow{3}{*}{\multicolumn{8}{|c|}{9 thursday 10 Friday }} \\
\hline & & & & & & & \\
\hline \multicolumn{2}{|l|}{$8: 00-9: 00$} & & & & & & \\
\hline \multicolumn{8}{|l|}{$9: 00-10: 00$} \\
\hline \multicolumn{8}{|l|}{$10: 00-11: 00$} \\
\hline \multicolumn{8}{|l|}{$11: 00-12: 00$} \\
\hline \multicolumn{8}{|l|}{$12: 00-1: 00$} \\
\hline \multicolumn{8}{|l|}{$1: 00-2: 00$} \\
\hline \multicolumn{8}{|l|}{$2: 00-3: 00$} \\
\hline \multicolumn{8}{|l|}{$3: 00-4: 00$} \\
\hline \multicolumn{8}{|l|}{$4: 00-5: 00$} \\
\hline & 13 Monday & 14 tuesday & 15 Wednesday & 16 & thursday & 17 & Friday \\
\hline \multicolumn{8}{|l|}{$8: 00-9: 00$} \\
\hline \multicolumn{8}{|l|}{$9: 00-10: 00$} \\
\hline $10: 00-11: 00$ & & & & & 6 & & \\
\hline $11: 00-12: 00$ & & & & & 7 & & \\
\hline $12: 00-1: 00$ & & & & & & & \\
\hline $1: 00-2: 00$ & & & & & & & \\
\hline $2: 00-3: 00$ & & & & & & & \\
\hline $3: 00-4: 00$ & & & & & & & \\
\hline $4: 00-5: 00$ & & & & & & & \\
\hline & 20 Monday & 21 tuesday & 22 Wednesday & प 23 & thursday & 24 & Friday \\
\hline $8: 00-9: 00$ & 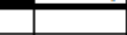 & & - & & 4 & & \\
\hline $9: 00-10: 00$ & & & & & 7 & & \\
\hline $10: 00-11: 00$ & & & & & 7 & & \\
\hline $11: 00-12: 00$ & & & & & 5 & & \\
\hline $12: 00-1: 00$ & & & & & & & \\
\hline $1: 00-2: 00$ & & & & & & & \\
\hline $2: 00-3: 00$ & & & & & & & \\
\hline $3: 00-4: 00$ & & & & & & & \\
\hline $4: 00-5: 00$ & & & & & & & \\
\hline & 27 Monday & $\mathbf{2 8}$ tuesday & 29 Wednesday & 30 & Thursday & 31 & Friday \\
\hline $8: 00-9: 00$ & & & 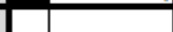 & & 5 & & \\
\hline $9: 00-10: 00$ & & & & & 6 & & \\
\hline $10: 00-11: 00$ & & & & & 5 & & \\
\hline $11: 00-12: 00$ & & & & & 6 & & \\
\hline $12: 00-1: 00$ & & & & & & & \\
\hline $1: 00-2: 00$ & & & & & & & \\
\hline $2: 00-3: 00$ & & & & & & & \\
\hline $3: 00-4: 00$ & & & & & & & \\
\hline $4: 00-5: 00$ & & & & & & & \\
\hline
\end{tabular}

Once entities (patients) are created and enter into the system, they are assigned attributes that will describe them throughout the simulation. Each patient is assigned with an attribute that will specify which entity type they represent and an attribute that changes their picture from a report to a person. A record module is then used to count the numbers of patients that will move through the system. Figure 3 shows the create, assign, and record modules for patient arrivals in Arena. 


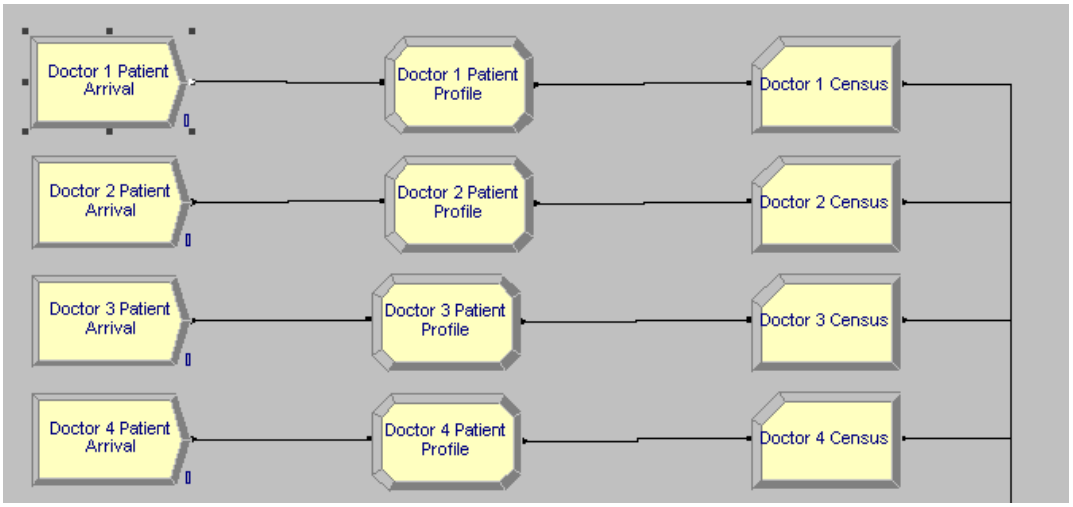

Figure 3: Arrival Section of Arena Module

Patients are then routed to the check in station where they seize and are processed by one of the 3 check in nurses. The patient entities seize the check-in staff based on a cyclical system. The check-in time is represented through a triangular distribution with a minimum of 4 minutes, mean of 8 minutes, and a maximum of 12 minutes. Then a decide module will separate the patients by the doctor they will be seeing based upon the attribute value assigned to their entity type. For example a patient with an attribute value of Coram Patient, will move enter the decide module and then exit on a path assigned to Dr. Coram. Following the decide module, a route module moves each patient to the specific doctor's station where they will seize the resources required to be serviced. Figure 4 shows the check-in logic used in Arena. 


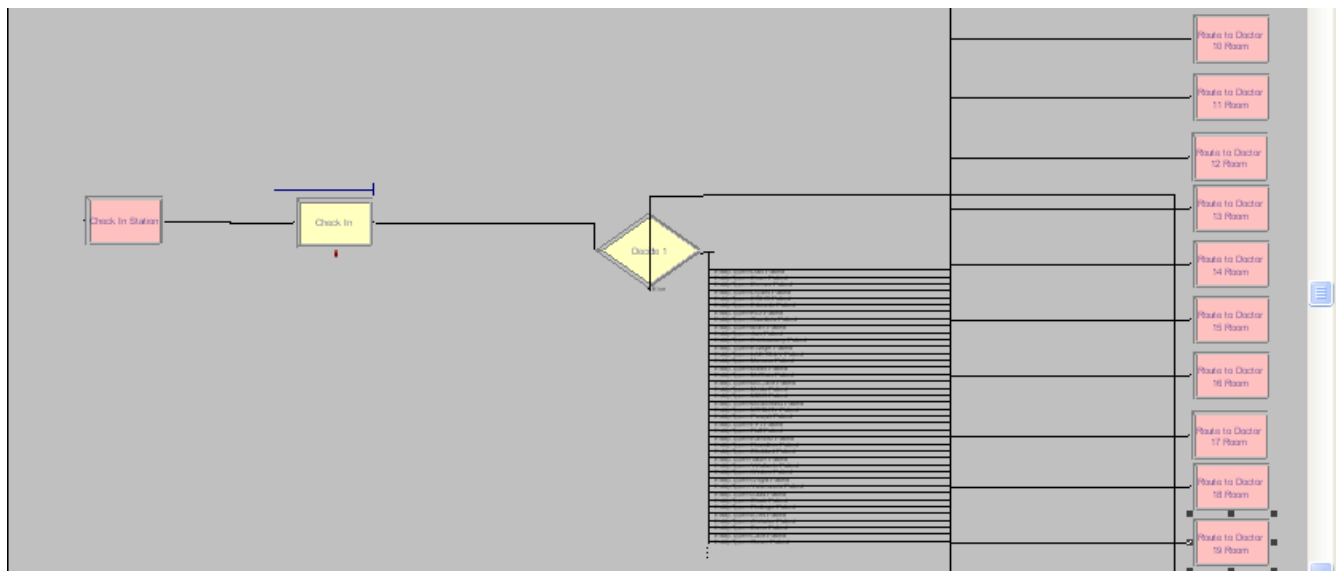

Figure 4: Check-in, Patient Type Identification, and Routing Logic in Arena After being routed to the specific doctor's station, the patients/entities will then seize resources necessary for processing by the doctor, a room, a Medical Assistant, and the necessary doctor. Once the doctor is finally seized they will be processed through a process module. The processing times are defined through a probability distribution developed from a year's worth of schedule appointment durations for each specified doctor. Unless the doctor uses all one durations, discrete probability functions were created from the probability of an appointment lasting a specified duration. A sample of the probability distributions of doctor processing times can be seen in Table III. 
TABLE III. PROBABILITY DISTRIBUTIONS FOR DOCTORS

\begin{tabular}{|c|c|c|c|c|c|c|c|c|c|c|c|c|c|c|c|c|c|c|c|c|}
\hline 4 & $E$ & $\mathrm{~F}$ & G & $\mathrm{H}$ & 1 & J & K & L & $M$ & $\mathrm{~N}$ & 0 & $P$ & Q & $R$ & $\mathrm{~s}$ & $T$ & $u$ & v & w & 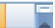 \\
\hline 1 & Doctor 1 & & Doctor 2 & & Doctor 3 & & Doctor 4 & & Doctor 5 & & Doctor 6 & & Doctor 7 & & Doctor 8 & & Doctor 9 & & Doctor 10 & \\
\hline 2 & 20 & 20 & 15 & 15 & 20 & 20 & 20 & 20 & 30 & 30 & 15 & 15 & 40 & 40 & 20 & 20 & 30 & 30 & 20 & \\
\hline 3 & 20 & 218 & 15 & 333 & 20 & 158 & $40^{\prime}$ & 190 & 30 & 177 & 15 & 1017 & 40 & 3 & 20 & 341 & 30 & 291 & 40 & \\
\hline 4 & 20 & 29 & 15 & 45 & 20 & 77 & $20^{\prime}$ & 80 & 30 & 46 & $15^{\prime}$ & 0 & 40 & 313 & 40 & 84 & 60 & 6 & 40 & \\
\hline 5 & 20 & 247 & 15 & 378 & 20 & 235 & 40 & 270 & 30 & 223 & 15 & 1017 & 40 & 51 & 20 & 425 & 30 & 55 & 40 & \\
\hline 6 & 20 & 0.882591 & 15 & 0.880952 & 40 & 0.67234 & 20 & 0.703704 & 30 & 0.793722 & 15 & 1 & 40 & 1 & 20 & 0.802353 & 30 & 6 & 20 & 0.6 \\
\hline 7 & 20 & & 15 & & 20 & & 20 & & 60 & & 15 & & 40 & 1 & 40 & & 30 & 358 & 20 & \\
\hline 8 & 20 & & 30 & & 20 & & 40 & & 30 & & 15 & & 40 & 369 & 40 & & 30 & 0.812849 & 20 & \\
\hline 9 & 20 & & 15 & & 20 & & 20 & & 30 & & 15 & & 40 & 0.00813 & 20 & & 30 & 0.01676 & 40 & \\
\hline 10 & 20 & & 15 & & 20 & & 20 & & 60 & & 15 & & 40 & 0.848238 & 20 & & 30 & 0.153631 & 20 & \\
\hline 11 & 20 & & 15 & & 20 & & 40 & & 30 & & 15 & & 40 & 0.138211 & 20 & & 30 & 0.01676 & 40 & \\
\hline 12 & 20 & & 15 & & 20 & & 20 & & 30 & & 15 & & 40 & 0.00271 & 20 & & 30 & & 40 & \\
\hline 13 & 20 & & 15 & & 20 & & 20 & & 30 & & 15 & & 40 & 0.00271 & 20 & & 30 & & 20 & \\
\hline 14 & 40 & & 15 & & 40 & & 20 & & 30 & & 15 & & 40 & & 20 & & 30 & & 40 & \\
\hline 15 & 20 & & 15 & & 20 & & 20 & & 60 & & 15 & & 40 & & 40 & & 30 & & 20 & \\
\hline 16 & 40 & & 15 & & 20 & & 20 & & 30 & & 15 & & 40 & & 40 & & 30 & & 20 & \\
\hline 17 & 40 & & 15 & & 20 & & 40 & & 30 & & 15 & & 40 & & 20 & & 30 & & 40 & \\
\hline 18 & 20 & & 30 & & 20 & & 20 & & 30 & & 15 & & 60 & & 40 & & 30 & & 40 & \\
\hline 19 & 20 & & 15 & & 20 & & 20 & & 30 & & 15 & & 40 & & 20 & & 30 & & 20 & \\
\hline 20 & 20 & & 15 & & 40 & & 40 & & 30 & & 15 & & 40 & & 40 & & 30 & & 40 & \\
\hline 21 & 20 & & 15 & & 40 & & 40 & & 30 & & 15 & & 40 & & 20 & & 30 & & 20 & \\
\hline 22 & 20 & & 30 & & 40 & & 20 & & 30 & & 15 & & 40 & & 40 & & 30 & & 20 & \\
\hline 23 & 20 & & 30 & & 40 & & 20 & & 30 & & 15 & & 40 & & 20 & & 30 & & 40 & \\
\hline 24 & 20 & & 15 & & 20 & & 20 & & 30 & & 15 & & 40 & & 40 & & 30 & & 40 & \\
\hline 25 & 20 & & 15 & & 20 & & 20 & & 30 & & 15 & & 40 & & 20 & & 30 & & 20 & \\
\hline 26 & 20 & & 15 & & 40 & & 40 & & 30 & & 15 & & 40 & & 20 & & 30 & & 40 & \\
\hline 27 & 20 & & 15 & & 20 & & 20 & & 30 & & 15 & & 40 & & 40 & & 30 & & 20 & \\
\hline
\end{tabular}

A full list of patient servicing duration functions can be found in Appendix II.

After the patients are finished being processed by the doctors, a release module is used to remove the room, medical assistant, and doctor from their seizure. Figure 5 shows doctor station, room seize module, MA seize module, doctor seize module, delay module for doctor processing and release module.

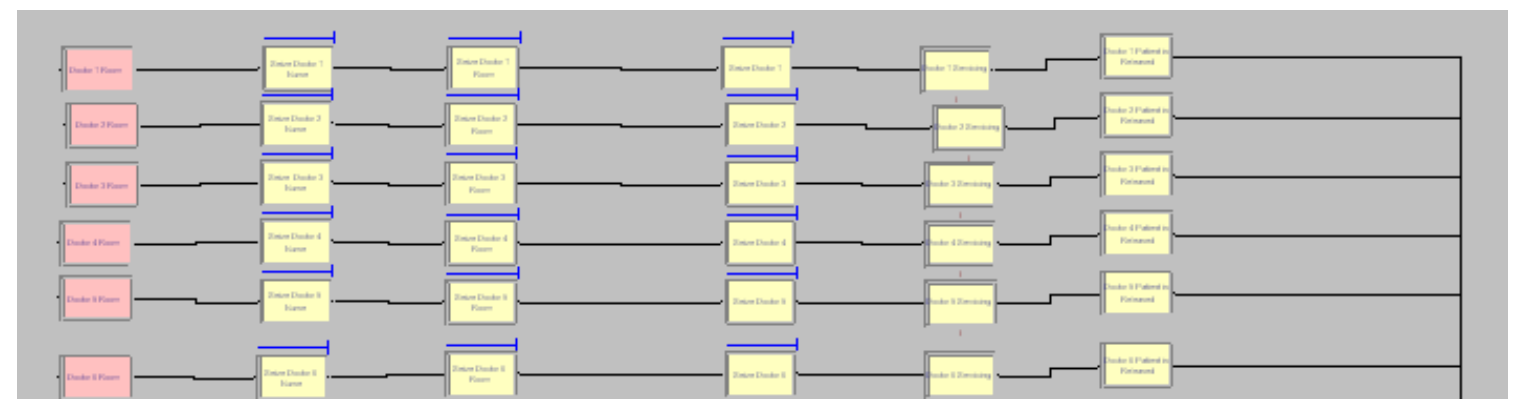

Figure 5: Patient Routing, Seizure, Processing, and Release Modules in Arena

The patients then exit the system and doctors, medical assistants, and exam rooms are freed to service other patients. Once the patients have moved from the exam room, check out team 
members will schedule follow-up appointments and review payment and insurance information. This process time is represented via a Triangular distribution with a minimum of 3 minutes, an average of 5 and a maximum of 7 minutes. The patient will then exit the system and is disposed in Arena.

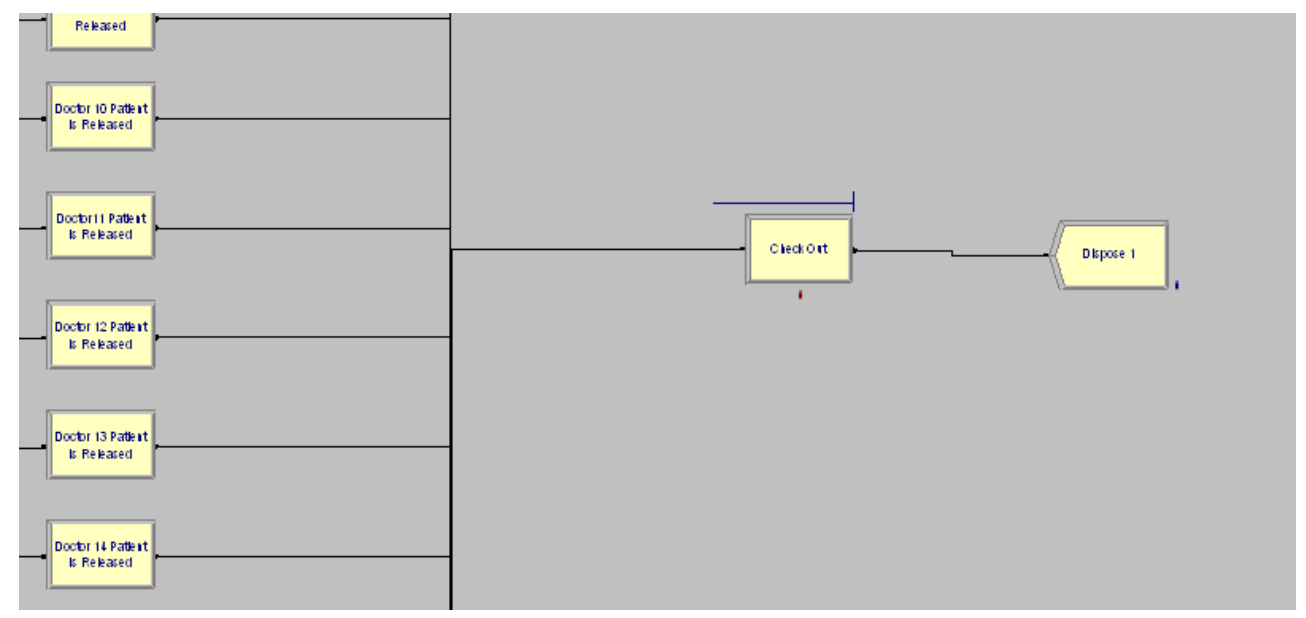

Figure 6: Check Out and Dispose Module for Patient Exit

Real time statistics were monitored throughout the simulation to understand how the process worked while events were happening. Date and time were monitored to give the user information on what point in the model is being shown. An expression totaling all current work in process patients for each doctor was used to calculate and then graph the total work in progress for the system's doctors. The level gives another visual representation of total work in progress. The green and white boxes show how resources are being used at the current time. The first two boxes are check-in staff, next 11 are medical assistants, following 24 are rooms, and last 4 are check-out staff. If the box is green then an entity has currently seized the resources, if it is white then the resource is free. Another graph was created to monitor the total 
number of entities created into the system at any given moment. Figure 7 shows the visual metrics review portion of the Arena model.

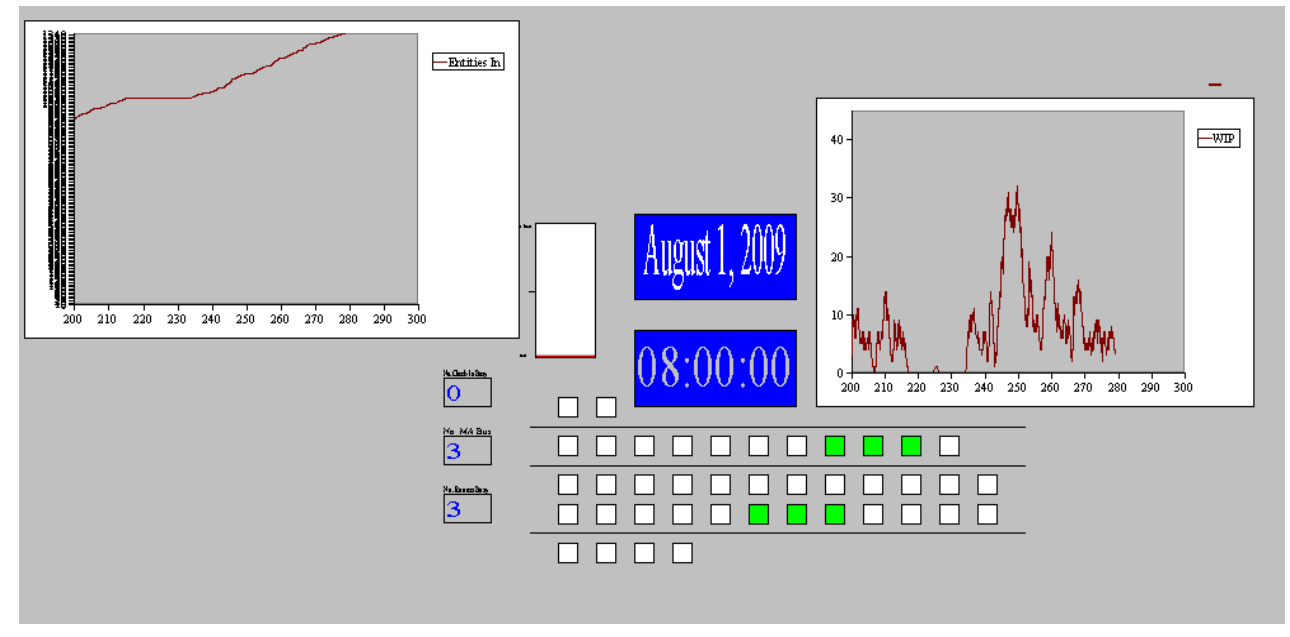

Figure 7. Real Time Model Statistics Section in Arena

This complete simulation model provides representation of actual process within the clinic. Its run length is 31 days at 9 hours per day. Again the model runs with actual patient arrival data and uses distributions for patient processing times derived from scheduled patient appointment durations. 


\section{RESULTS}

\section{A. Verification and Validation}

A key step before accepting the results of the simulation model is to ensure the model has been validated. Validation of a model ensures that the model is an accurate description of the real world system it is modeling. Verification ensures that the model is correctly describing the modeler's conceptual description of the system. The model created for the outpatient center has been validated to make certain that it is correctly describing the process at hand.

The model verification process for the outpatient clinic was fairly simple. The process was studied through walk through analysis and observation in the facility. Discussions with staff also aided in the modeler's understand of how things worked in the system. The modeler's then described the process within the Arena software and made assumptions when it was impractical to model exact situations. With the aforementioned assumptions, the developer is confident that the Arena model accurately represents the conceptual description of the system.

The validation of this simulation was performed throughout its development. Care was taken to ensure that actual data was used and only relevant information was included. Patient arrival and doctor processing times were extracted directly from system data provided by the outpatient center. Based on this data, the clinic was able to see 1441 patients in July of 2009 . The simulation model created and processed 1460 patients over the same simulated month. This results in a $1.3 \%$ error between the actual and simulated results. Figure 8 shows the expected patient output compared to the simulated patient output. 


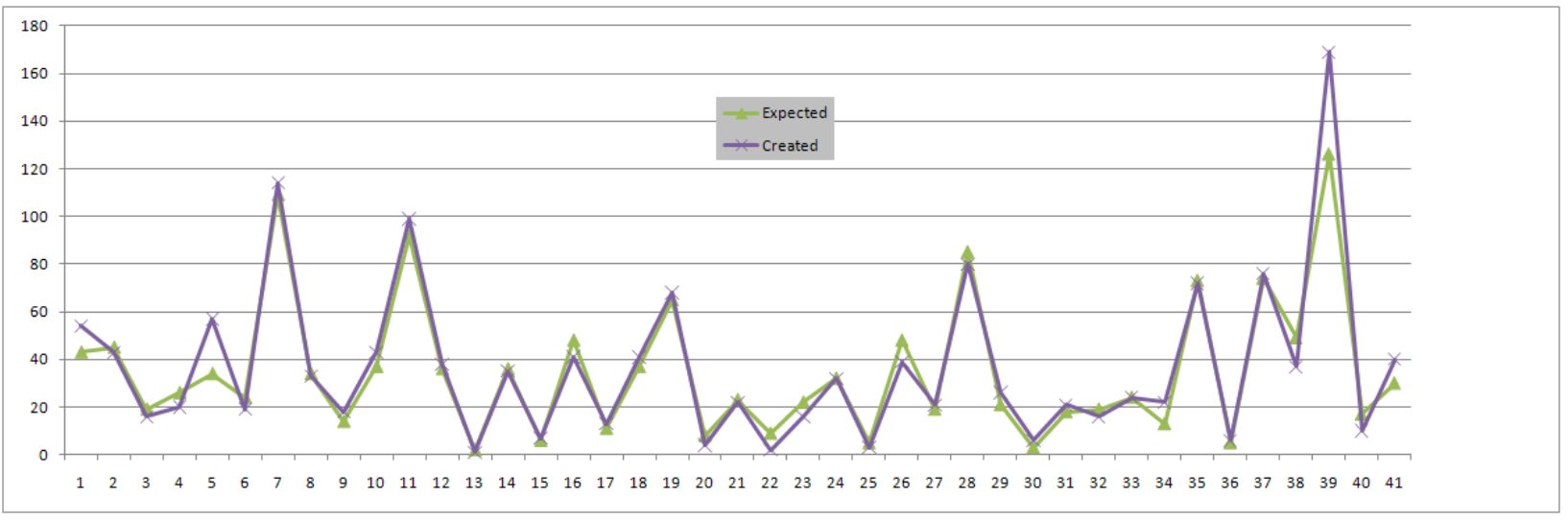

Figure 8. Expected vs. Created Patients for July 2009

As it can be seen from above, the real world and simulation systems are operating very closely. With the confidence that the arena simulation is validated and verified, it can be now used to study the performance metrics within the outpatient center.

\section{B. Model Output}

The simulation model was run for 22 days to replicate the month of July 2009. The model operated with 9 hour days, starting at 8:00 A.M. and concluding at 5:00 P.M. 41 different patient types were created throughout the model, with a total of 1460 patients being seen in the operating month. Patient time was broken down into 3 categories, value added or processing time, wait time, and transfer time. Work in Progress (WIP) average service time per entity, entity waiting time per resource, and utilization rates were also reported through the model.

The value added time for a patient ranged from 23.5 minutes to 56.74 minutes with an average patient time of 38.69 minutes. Average patient waiting times ranged from 3.63 minutes to 133.37 minutes. Overall 41 doctors, average patient waiting time was 47.11 minutes. Waiting time to check in was 1.82 minutes and check out was 0.147 seconds. It should be noted that 
these waiting times are averages and are tied to the number of patient serviced. For example, a certain doctor's patient waiting time was over 2 hours, but that doctor saw only 6 patients all month.

Seeing as transfer time for each patient was identical, total time in system will provide greatest value for analysis. On average patients spent 89.91 minutes in the system. This time includes check in time, routing time, waiting time, servicing time, and check out time. The highest time spent in system was, on average, 176.45 minutes and the least was only 42.86 minutes in the system. Throughout the month simulation there was an average WIP for the total system of 12.23 patients. Average instantaneous WIP for doctors was 0.298 . The highest WIP was 1.53 patients and the lowest was .00508 patients. Figure 9 shows simulated compated to actual time in system.

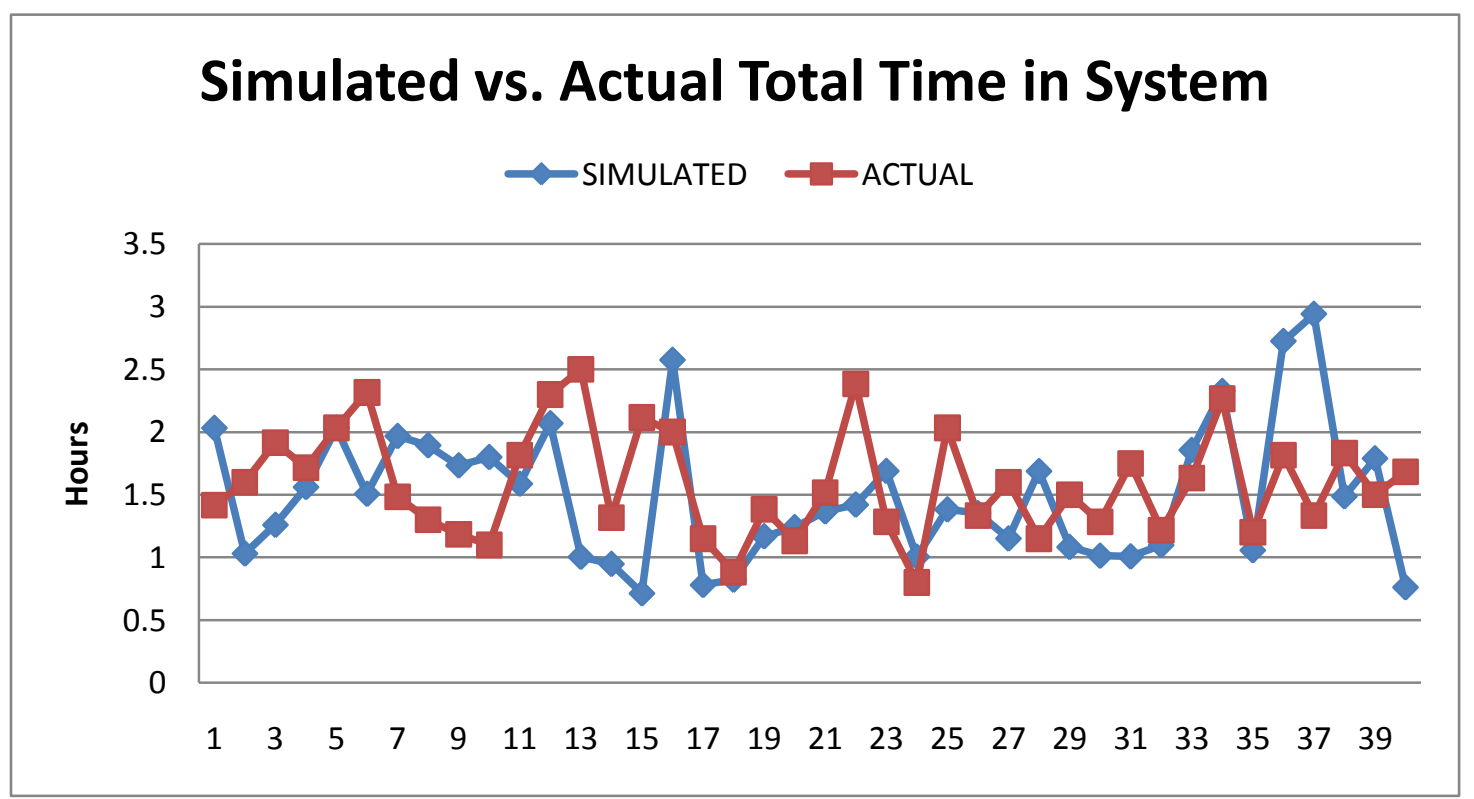

Figure 9. Acutal vs. Simulated Time in System 
Time per entity provides a measure of the average time an entity (patient) spends within certain processes. These servicing times come from the distribution functions that were developed using the actual processing data. On average processes within the outpatient center took 24.07 minutes. Check out was the shortest process with an average time of 4.99 minutes.

Accumulated time represents the sum of time a resource spends processing entities throughout the simulated time. For this simulation, we used 22 days a 9 hours per day for a total simulated time of 198 hours. The average resource was busy for 20.5 hours throughout the model simulation. It should be noted that doctors only work 1-3 half days per week and some only work one half day per month.

Average time spent waiting in queue for a nurse is 22.12 minutes and no time was spent waiting in queue to secure a room. On average there were 2.9912 patients waiting for a nurse at any time during the system. 4.1067 patients were waiting for doctors on average during the system. This equates to about 0.10016 patients per doctor. Some doctors never had patients waiting for them, but some doctors had as much as 15 patients waiting in queue during the simulation.

Utilization for the check in staff was about $32 \%$ for the 3 available. The check out staff utilization was about $15 \%$. MA utilization ranged from 60 to $69 \%$ for each of the 11 Medical Assistants. Exam room utilization ranged from 23 to $34 \%$ with an average of $29.09 \%$. 
Looking at utilization rates based on day of week supports the initial theory that Tuesday and Wednesday are the busiest days in the office. Figure 10 shows the daily utilization rates for the clinic.

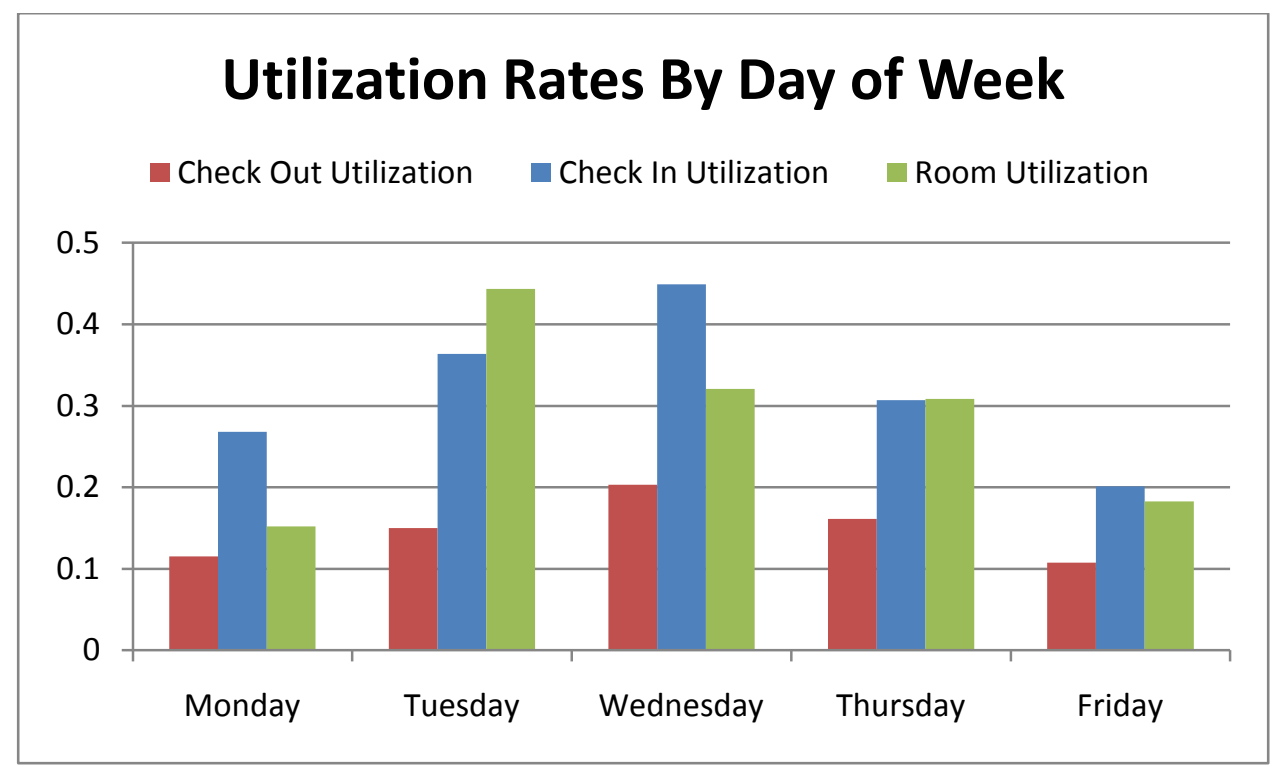

Figure 10. Resource Utilization Rates by Day of Week

Due to the fact that doctors are only in the office when they have scheduled appointments, calculating doctor utilization is difficult. In order to calculate utilization rates for doctors the author took accumulated hours busy from the Arena output and divided it by the accumulated hours the doctors were in the office. It is assumed that doctors are in the office for the complete half day if they have patients scheduled within a half day. A half-day is defined as 4 hours. The doctor utilization rates range from $100 \%$ to $7.57 \%$ with an average of utilization of $54.46 \%$. 


\section{DISCUSSION OF RESULTS}

From the above results, much can be learned about the operation of the outpatient center. There are a few noticeable sources of variation present in the system. Patient waiting times are highly variable based on which doctor a patient is seeing. Related to patient waiting, doctor utilization rates are also highly variable. Other parts of the clinic run very efficiently. The check in and checkout processes are very smooth and add only slightly to overall patient experience time. Also room availability is high for the clinic potentially allowing for more work to be introduced into the clinic.

On average patients spend about 89 minutes in the clinic, which seems very reasonable based upon the author's time spent down at the center. Due to the nature of outpatient clinics and the type of medicine being practiced number of patients scheduled and processed can vary greatly by doctor. Upon further study of the clinic this becomes highly evident as a major source of variability in the system. This variability paired with the lack of flexibility within the doctor's schedules makes for a system that can run efficiently one day and be completely backed up another.

Check in staff utilization was over double that of check out staff. It may be necessary to let one of the check out staff work part of their day doing check in at peak hours. Although MA utilization may not seem too high (60-69\%), it must be considered that not all of their duties were simulated within this model. Their chart preparation and paperwork handling activities were only a few of the duties that were not included in this model. It is important to note that the average number of patients waiting for a nurse (2.9912) and the average number of patients 
waiting for a doctor (4.1067) are relatively close. If more clinics were held within the outpatient center, doctors and MAs could be added to the current staff at slightly lower rate. Exam room utilization is also relatively low (29\%) so more staff could easily be added without expensive infrastructure changes.

Overall the simulated system operates very closely to that of the observed real life system. Upon conclusion of a detailed performance metrics review, obvious areas for improvement became obvious. Schedule smoothing and patient processing time evaluations could greatly impact the daily operations within the clinic. Data from this simulation could be used to support future staffing level decisions. The main take away from this detailed analysis should be a greater understanding of performance metrics and how they affect the operations within the University of Louisville Outpatient Center. 


\section{CONCLUSIONS, RECOMMENDATIONS, and FUTURE RESEARCH}

\section{A. CONCLUSIONS AND RECOMMENDATIONS}

The simulation model for the University of Louisville Outpatient Center provides valuable insight into the operational statistics that control the day-to-day function of the area. The model used actual data from the month of July 2009 to drive patient arrivals and patient processing times. Deterministic probability functions were used to describe patient processing time for each of the 40 doctors in the system. The patient flow process was modeled using the Arena simulation software. The finished model was validated and verified and then ran for 31, 9 hour days or 279 hours. Finally the center's performance metrics were studied to provide recommendations for the future operations of the system.

Although the outpatient center was operating adequately under its current order, improvements could be made to improve efficiency. Due to the relatively low utilization rates of the exam rooms, it seems that more doctors could hold clinics with the outpatient center. If more doctors were to be added to the system it would make sense, based on the number of patients waiting for both doctor and MA, that MAs would be added an almost an equal rate as doctors are added. Since utilization for check out staff is almost double that of check in, a member of the check out team could potentially work part of their day at the check in counter to balance out workload. Finally, since patient total time is system is so highly variable based on the doctor, it would make sense for each doctor to look at the amount of time they are scheduling for appointments and see if those time slots are still valid based on actual patient processing. 


\section{B. FUTURE RESEARCH}

The current model works well for providing a current state analysis of the outpatient center's performance measures. Someone who has extensive Arena modeling knowledge can update it to provide a case-by-case analysis. This would limit the population of persons who can make process changes and see potential outputs. In order to facilitate utilization of the model by the outpatient center staff work needs to be done to increase usability. Future work on this simulation model would allow users with very little Arena simulation knowledge to update patient arrivals via Excel spreadsheet.

Animation provides a visual representation of the logic supporting the model. The model has been set up with route and station blocks, which will aid in adding animation at a later time. Animation would need to be added to help those not familiar with Arena to understand the processes and start to put trust in the output from the model. A fully animated model with excel based patient arrival inputs could be easily utilized and understood by almost all personnel within the outpatient center. 


\section{REFERENCES CITED}

Bakker, P., Das, S., Edward, G., Elkhuizen, S., Hollman, M., Hontelez, J., Lemaire, L., and Preckel, B. 2008. Simulation to analyse planning difficulties at the preoperative assessment clinic. In British Journal of Anaesthesia 100: 195-202Bakker, P., Das, S., Elkhuizen, S., Hontelez, J. 2006. Using computer simulation to reduce access time for outpatient departments. In Quality and Safety in Health Care 16: 382-386

Barnes, C., Benson, C., Quiason, J., McGuiness, D. 1997. Success stories in simulation in health care. In Proceedings of the 1997 Winter Simulation Conference 1280 - 1285

Bennett, J., Worthington, D. 1998. An example of a good but partially successful OR engagement: improving outpatient clinic operations. In Interfaces 28: 56-69

Bevan, G., Coyle, E., Fone, D., Hollinghurst, S., Lester, N., Palmer, S., Roberts, K., Round, A., Weightman, A., 2003, Systematic review of the use and value of computer simulation modeling in population health and health care delivery. In Journal of Public Health Magazine 25: 325-335

Brailsford, S., Harper P., Sykes, J. 2006. Incorporating human behavior in healthcare simulation models. In Proceedings of the 2006 Winter Simulation Conference 466- 472

DeFlitch, C., Medeiros, D., Swenson, E., 2008. Improving patient flow in a hospital emergency department. In Proceedings of the 2008 Winter Simulation Conference 1526 - 1531

Denton, B., Huschka, T., Narr, B., 2008. Using simulation in the implementation of an outpatient procedure center. In Proceedings of the 2008 Winter Simulation Conference 1547 - 1552

Dexter, F., 1999. Design of appointment systems for preanesthesia evaluation clinics to minimize patient waiting times: a review of computer simulation and patient survey studies. In Anesthesia and Analgesia, 4: 925

Fetter, R. and Thompson, J. 1965. The simulation of hospital systems. Operations Research 13: 689-711.

Gaba, D., 2004. The future vision of simulation in health care. In Quality and Safety in Health Care 13: 2-10

Jun, J. B., S. H. Jacobson, and J. R. Swisher. 1999. Application of discrete-event simulation in health care clinics: a survey. Journal of the Operational Research Society, 50:109-123.

Kuljis, J., R. J. Paul, and L. K. Stergioulas. 2007. Can health care benefit from modeling and simulation methods in the same way as business and manufacturing has? In Proceedings of the 2007 Winter Simulation Conference, 1449-1453. 
Liu, L. and Liu, X. 1998. Block appointment systems for outpatient clinics with multiple doctors. In The Journal of Operational Research Society 49: 1254-1259

Miller, M., LaVecchia, R., Shahi, N., 2008. Allocating outpatient clinic services using simulation and linear programming. In Proceedings of the 2008 Winter Simulation Conference 1637 - 1644

Takakuwa, S., and Wijewickrama, A. 2008 Outpatient appointment scheduling in a multi facility system. In Proceedings of the 2008 Winter Simulation Conference 1563-1571 
APPENDIX I. PATIENT FLOW CHART

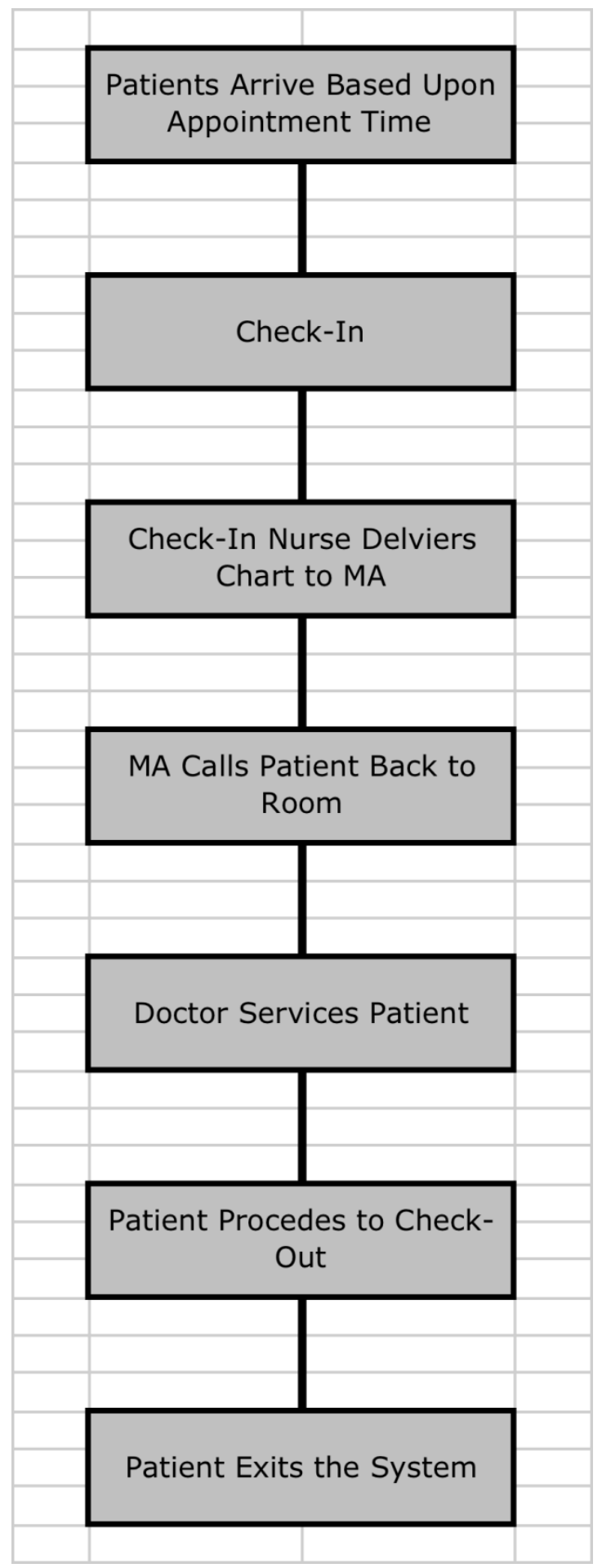




\section{APPENDIX II. PATIENT SERVICE TIME DISTRIBUTIONS}






\section{APPENDIX III. PATIENTS EXPECTED COMPARED TO ENTITIES CREATED}

\begin{tabular}{|c|c|c|c|}
\hline & & \multicolumn{2}{|c|}{ No. of Patients: } \\
\hline \multicolumn{2}{|c|}{ DOCTOR } & Expected & Created \\
\hline Doctor & 1 & 43 & 54 \\
\hline Doctor & 2 & 45 & 43 \\
\hline Doctor & 3 & 19 & 16 \\
\hline Doctor & 4 & 26 & 20 \\
\hline Doctor & 5 & 34 & 57 \\
\hline Doctor & 6 & 24 & 19 \\
\hline Doctor & 7 & 109 & 114 \\
\hline Doctor & 8 & 34 & 33 \\
\hline Doctor & 9 & 14 & 18 \\
\hline Doctor & 10 & 37 & 43 \\
\hline Doctor & 11 & 92 & 99 \\
\hline Doctor & 12 & 36 & 38 \\
\hline Doctor & 13 & 2 & 1 \\
\hline Doctor & 14 & 36 & 35 \\
\hline Doctor & 15 & 6 & 7 \\
\hline Doctor & 16 & 48 & 41 \\
\hline Doctor & 17 & 11 & 13 \\
\hline Doctor & 18 & 37 & 41 \\
\hline Doctor & 19 & 65 & 68 \\
\hline Doctor & 20 & 8 & 4 \\
\hline Doctor & 21 & 23 & 22 \\
\hline Doctor & 22 & 9 & 2 \\
\hline Doctor & 23 & 22 & 16 \\
\hline Doctor & 24 & 32 & 32 \\
\hline Doctor & 25 & 5 & 3 \\
\hline Doctor & 26 & 48 & 39 \\
\hline Doctor & 27 & 19 & 21 \\
\hline Doctor & 28 & 85 & 80 \\
\hline Doctor & 29 & 21 & 26 \\
\hline Doctor & 30 & 3 & 6 \\
\hline Doctor & 31 & 18 & 21 \\
\hline Doctor & 32 & 19 & 16 \\
\hline Doctor & 33 & 24 & 24 \\
\hline Doctor & 34 & 13 & 22 \\
\hline Doctor & 35 & 73 & 72 \\
\hline Doctor & 36 & 5 & 6 \\
\hline Doctor & 37 & 74 & 76 \\
\hline Doctor & 38 & 49 & 37 \\
\hline Doctor & 39 & 126 & 169 \\
\hline Doctor & 40 & 17 & 10 \\
\hline Doctor & 41 & 30 & 40 \\
\hline TOTAL & & 1441 & 1460 \\
\hline
\end{tabular}

